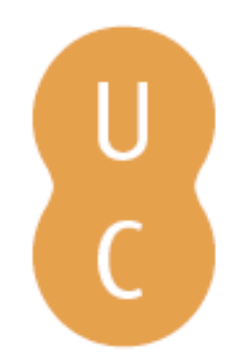

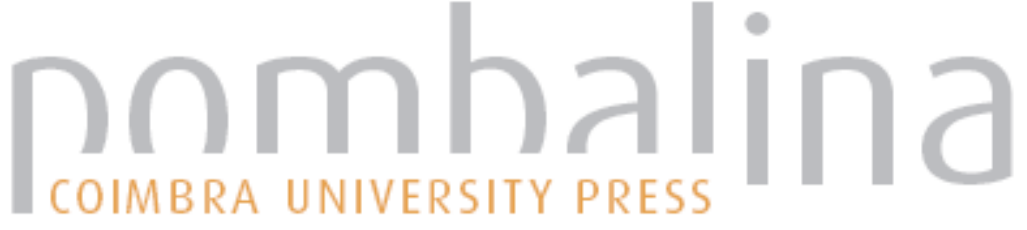

\section{Effects of maturation on potential predictors of talent in soccer}

Autor(es): $\quad$ Jorna, Casper; Elferink-Gemser, Marije T.; Visscher, Chris

Publicado por: Imprensa da Universidade de Coimbra

URL

persistente:

URI:http://hdl.handle.net/10316.2/38856

DOI:

DOI:http://dx.doi.org/10.14195/978-989-26-1169-3_9

Accessed : $\quad$ 26-Apr-2023 13:19:32

A navegação consulta e descarregamento dos títulos inseridos nas Bibliotecas Digitais UC Digitalis, UC Pombalina e UC Impactum, pressupõem a aceitação plena e sem reservas dos Termos e Condições de Uso destas Bibliotecas Digitais, disponíveis em https://digitalis.uc.pt/pt-pt/termos.

Conforme exposto nos referidos Termos e Condições de Uso, o descarregamento de títulos de acesso restrito requer uma licença válida de autorização devendo o utilizador aceder ao(s) documento(s) a partir de um endereço de IP da instituição detentora da supramencionada licença.

Ao utilizador é apenas permitido o descarregamento para uso pessoal, pelo que o emprego do(s) título(s) descarregado(s) para outro fim, designadamente comercial, carece de autorização do respetivo autor ou editor da obra.

Na medida em que todas as obras da UC Digitalis se encontram protegidas pelo Código do Direito de Autor e Direitos Conexos e demais legislação aplicável, toda a cópia, parcial ou total, deste documento, nos casos em que é legalmente admitida, deverá conter ou fazer-se acompanhar por este aviso. 


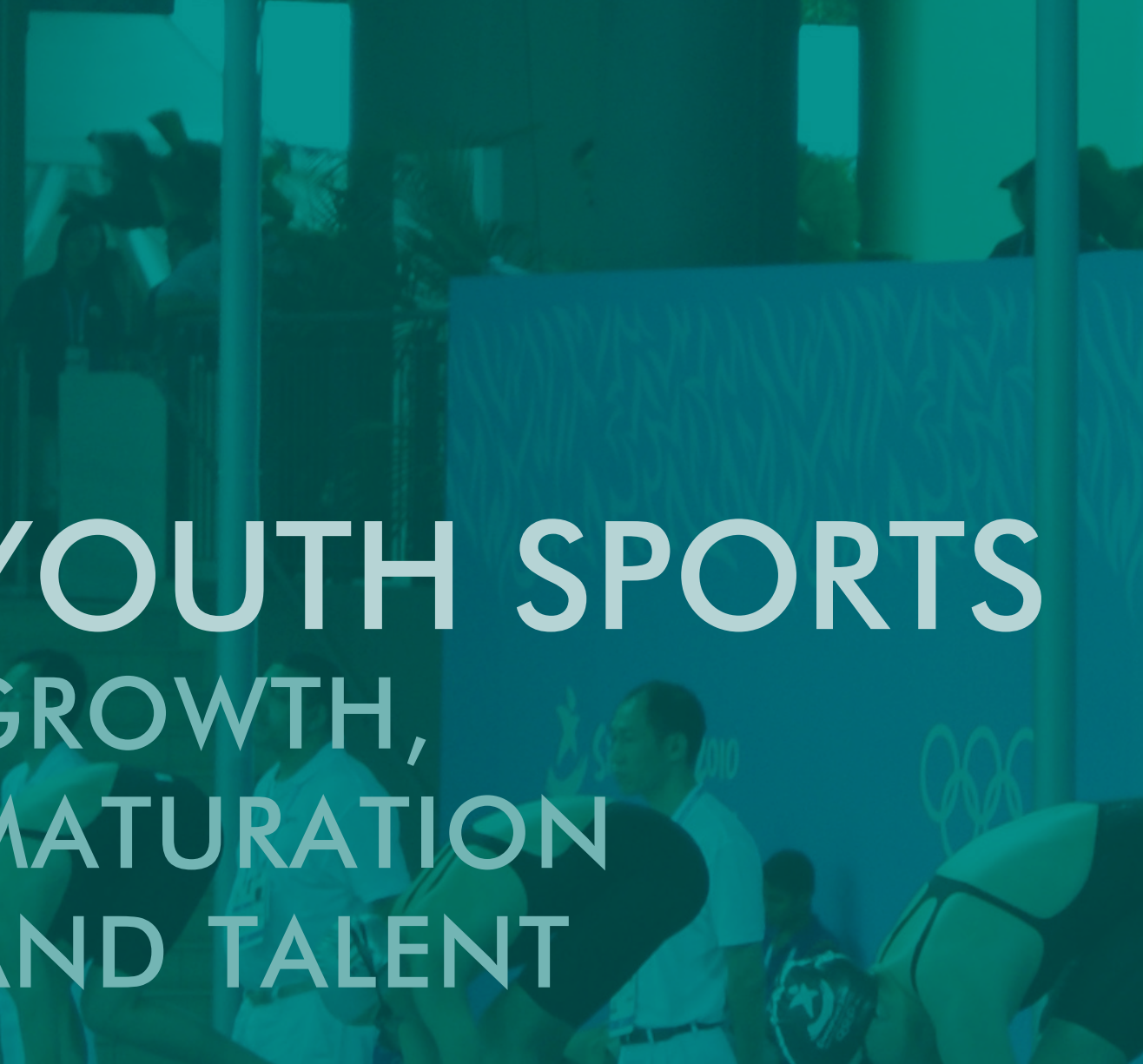

MANUEL J. COELHO E SILVA ANTÓNIO J. FIGUEIREDO MARIJE T. ELFERINK-GEMSER ROBERT M. MALINA

\section{EDITORS}

2. ' EDIÇÃO

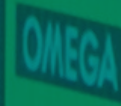

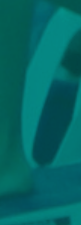




\title{
CHAPTER 9: EFFECTS OF MATURATION ON POTENTIAL PREDICTORS OF TALENT IN SOCCER
}

\author{
Casper Jorna \\ Marije T Elferink-Gemser \\ Chris Visscher
}

\section{INTRODUCTION}

The basic definition of talent identification lies within the recognition of a natural gift or ability of a superior quality that is at least partially innate and affected by numerous environmental conditions (Williams et al, 2000b; Pearson et al., 2006;). Another aspect of talent is performing better than the rest in a certain domain. Furthermore, talent is considered to be domain specific. Williams et al. (2000b) suggested that talent may not be evident at an early age but there will be some indicators that enable trained individuals to identify its presence. Sport science is making an increasing effort in discovering the important predictors and characteristics of talent in soccer (Williams et al., 2000a). Young potentially talented soccer players arrive at the soccer academy as early as age 6 or 7 .

In elite soccer there was found to be an over representation of players born in the first quarter of the selection year (Helsen et al., 2005; Vaeyens et al., 2005). This bias towards an overrepresentation is referred to as the RAE [Relative Age Effect]. The explanation often focuses on the advantage of size. Those born early in a particular year, or in other words those who are older at the selection date within the same age category, are, on average: taller, heavier, stronger and more developed than those born later in that year. In most sports, as in soccer, size may be a significant factor in it self. Especially when strength, power and speed are important for different aspects of the game (Helsen et al., 2005; Vaeyens et al., 2005). Thus, when young players tend to be biologically mature coaches and trainers are biased to selecting them. As a result, maturation might also have an effect on the selection and prediction of talent.

When considering the large and ever increasing amount of research done in the soccer domain it is surprising that the effects of maturation on potential predictors of talent has had so little attention thus far. The first publications of maturational effects on talent characteristics started to appear around 1990 but most research is done in the last 10 years (Table I). This 
literature-based review assesses different studies done on biological maturation in soccer within the context of potential predictors of talent. The aim of this review is to assess the effects of maturation on potential predictors of talent in the soccer population within a multi-disciplinary approach. In the discussed research there is great diversity of methods used to establish biological maturation. After an introduction in the important predictors of talent, and maturation assessment methods, the available literature was examined.

\section{METHODOLOGY}

In the search for relevant articles the following databases have been consulted PubMed, Web of Science and Google Beta. The keywords (physical, biological or sexual) "maturation", "growth", "puberty", "adolescents", "youth" or "development" were used alone or in combination with the words "soccer", "football" or "talent (identification)", "elite" and/or "high potential". The articles were refined with terms closely associated with physical-, physiological- and/or psychological characteristics. Because of the scarcity of studies on maturation there was no date constraint on the found literature. Since most studies are of the last decade, more focus will be on this period.

Selected articles were reviewed on the following criteria; Type of study (cross-sectional or longitudinal), number of a participants (only males will be discussed), origin of subjects, age range, competition level of the participants (elite, sub-elite, non-elite, or recreational), appearance or absence of control group, aspects concerning player position on the field, maturation assessment method, onset of maturation (early, on-time or late), and maturational effects on potential predictors of talent in soccer.

\section{RESULTS}

\section{Talent predictors in soccer}

Because of the broad demands of a soccer game, a multidisciplinary approach is essential in the research and development of talent (Pearson et al., 2006; Vaeyens et al., 2006; Williams et al, 2000b). It is suggested that the potential prediction of talent lies in the physical, physiological, psychological and sociological aspects of soccer (Pearson et al., 2006; Vaeyens et al., 2006; Williams et al, 2000b). 


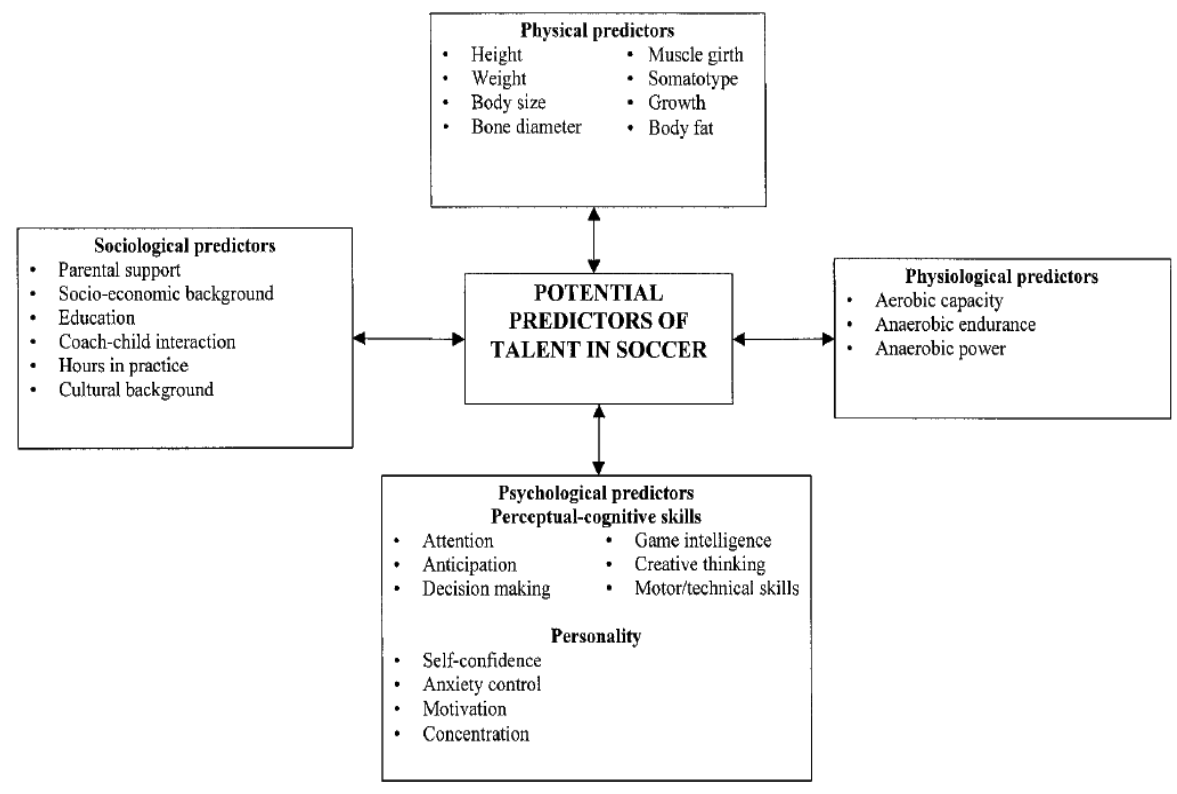

Figure I. Potential predictors of talent in soccer (Williams et al, 2000b).

a) Physical predictors

Elite adolescent players tend to be taller and heavier than their peers. This difference declines when adulthood is reached (Beunen et al., 1997; Cacciari et al., 1990; Hansen et al., 1999a). Williams and Reilly (2000b) suggested that the physical characteristics of players are related to performance. The somatotype, mostly mesomorph, and physique of elite adolescent players is comparable to that of elite adult players (Williams et al, 2000b; Reilly et al., 2000a). The adult stature is strongly influenced by genetics whereas other physical predictors, for instance muscle mass and percentage adipose tissue are more influenced by training and dietary. The under-16 team fat percentages are reported to be comparable to elite adult players, which is about I 1\% of adipose tissue (Reilly et al., 2000a). When it comes to height Reilly et al. (2000a) reported several studies where certain playing positions have a tendency for taller and heavier players (e.g., defenders and goalkeepers) even though tall forwards and midfielders have also been reported. The variability might influence the tactical role allocated to the individual player within the team. 


\section{b) Physiological predictors}

The activity pattern during a match, of non-elite adolescent players shows many differences when compared to elite adult players. However the activity pattern of elite adolescent players does not differ much from the activity pattern seen in elite adult players (Strøyer et al., 2004). Bangsbo et al. (1994) reported that the average energy demand of a soccer match is around $5700 \mathrm{Kj}$ for a $75 \mathrm{~kg}$ adult man with a VO2-max of $60 \mathrm{ml} / \mathrm{kg} / \mathrm{min}$. The average maximal oxygen intake for elite adult players is reported to be in the range of 55 to 69 $\mathrm{ml} / \mathrm{kg} / \mathrm{min}$ with higher average values for better teams. The variation in oxygen uptake is partly due to different playing positions (Strøyer et al., 2004). During a match the relative load approximates $70-80 \%$ of the $\mathrm{VO}_{2}$-max for elite adult and elite adolescent players. Elite adult players have an average Heart Rate (HR) of about 160-165 beats per minute (bpm) depending on the match intensity (Bangsbo et al., 1994; Reilly et al., 2000a). The HR of an elite 12 year old is higher, 198-202 bpm (Armstrong et al, 1997; Strøyer et al., 2004). During a match high intensity sprints alternate with low intensity walking and jogging. The critical phases of play, for instance winning possession of the ball or scoring opportunities are mostly anaerobic while the predominant metabolic (energy demands) pathways are aerobic. As such, soccer is classified as a high intensity intermitted sport (Lemmink et al., 2004).

In the adolescent period ( $13-16$ years), the $\mathrm{VO}_{2}$-max is in the range of 55 increasing to $69 \mathrm{ml} / \mathrm{kg} / \mathrm{min}$ for elite players and in the range of 56 declining to $52 \mathrm{ml} / \mathrm{kg} / \mathrm{min}$ for the non-elite players (Baxter-Jones et al., 1993; Hansen et al., 2002). Considering the wide range of $\mathrm{VO}_{2}-\mathrm{max}$ values reported to be acceptable at highest levels, $\mathrm{VO}_{2}$-max appears not to be a suitably sensitive measure on its own of performance capability. Rather there seems to be a minimum requirement of $60 \mathrm{ml} / \mathrm{kg} / \mathrm{min}$ in modern-day elite adult soccer (Reilly et al., 2000a). VO2-max for elite adolescent players from age 12 and up, must be higher than $58 \mathrm{ml} / \mathrm{kg} / \mathrm{min}$ (Hansen et al., 2002).

On average an adult match calls for an all out sprint every 90 s and high intensity effort every 30s. In elite adolescent soccer about $7.9 \%$ to $9 \%$ of the time is spend as high intensity running (Strøyer et al., 2004). Muscle strength is suggested to be relevant for kicking the ball, tackling, and tolerating physical contact. The inter-limb coordination, and balance between flexors and extensors are important for injury prevention (Reilly et al., 2000a). Because of the delayed development in anaerobic energy pathways in adolescence, the relative contribution to the total energy demand is less. For instance, in a maximal effort of less then 60 seconds children derive $60 \%$ of the total energy demand from anaerobic sources while this is $80 \%$ in adult athletes. It is hypothesised that adolescents are less able than adults to affect ATP rephosphorylation through glycolysis during high intensity exercise (Van Praagh 
et al., 2002). However, children have a lower lactate production and recover faster after intense maximal exercise bouts. Anaerobic power and capacity are measured with several different methods. The amount of energy obtained by anaerobic processes cannot yet be measured directly (Armstrong et al., $200 \mathrm{lb}$ ). Several studies reported lower anaerobic power for soccer players compared to sprinters and middle distance runners but 10\% - 20\% more anaerobic power when compared to age matched control groups (Reilly et al., 2000a). The anaerobic capacity increases with maturation until that of adults is reached after the teenage years (Reilly et al., 2000a). High anaerobic power and capacity are necessary for top class performance in soccer.

c) Psychological predictors.

In soccer there are obvious physical and physiological demands like $\mathrm{VO}_{2}$-max and sprinting ability. Nevertheless, it is well recognized that the psychological aspects often distinguish between elite and non-elite peers (Morris et al., 2000). Psychological predictors can be subdivided in perceptual-cognitive skills and personality (figure I).

One of the promising approaches to talent development is the measurement of perceptual-cognitive skills such as anticipation and decisionmaking (Williams, 2000; Williams et al, 2000b). Elite adolescent players show consistent differences when compared to their non-elite peers (Reilly et al., 2000b; Williams, 2000). When tested they are: "faster and more accurate in recognizing patterns of play; better at anticipating the actions of their opponents based on contextual information; characterized by more effective and appropriate visual search behaviour; more accurate in their expectations of what is likely to happen given a certain set of circumstances" (Williams and Reilly, 2000b, Page 66I). In addition, they score higher on technical skill tests (Malina et al., 2005; Malina et al., 2007b). Furthermore, cognitive aspects like higher school grades and greater creativity are associated with elite adolescent players (Williams, 2000).

Morris (2000) mentioned several important personality traits that are associated with soccer such as "Emotionally stable, tough and realistic, conventional, and cold and aloof" (Morris (2000), page 7|8). A frequently heard term when it comes to personality traits is motivation (Morris et al., 2000). In research by Reilly et al. (2000b), motivational orientation is found to be an important discriminating factor in differentiating between elite and nonelite players. Elite adolescent players seem to adopt a more task orientated instead of ego orientated approach as well as being more self-confident than their non-elite peers (Reilly et al., 2000b). Task orientation and success have been correlated with endorsement of effort and persistence (Van-Yperen et al., 1999). Elite adolescent players are also less likely to experience somatic 
anxiety than their less successful peers and tend to perceive cognitive and somatic anxiety as facilitative to performance (Reilly et al., 2000b).

\section{d) Sociological predictors}

Williams and Reilly (2000b) argued that an important determinant for success is socialisation into the particular culture. Parents are typically the ones introducing a child in the world of organized soccer. Parental support and a positive attitude towards the involvement in soccer are very important. However, friends and coaches are the ones who have an extremely important role in stimulating the child in further involvement. Furthermore, social class has a significant effect upon participation. Even though soccer is originally thought of as a sport for the working classes, it becomes ever more clear that children from middle class and up have an advantage because of financial support, greater flexibility, and more mobility and support in transport (Williams et al, 2000b).

Also, the role of the coaches and their involvement is important in the development of the child. Elite players have great respect towards their coach. A good coach knows when to push players and when to reduce or intensify the training, expectations and support. Furthermore, it is suggested that ten years of extensive practice are needed to achieve expertise (Williams et al, 2000b).

\section{Maturation}

The terms growth and maturation are often used interchangeably when describing the physical and biological development of children and adolescents. Nevertheless the terms refer to a different process. Beunen et al (2004) and Malina et al. (2004a) described growth as an increase in the size of the body as a whole or the size attained by specific parts of the body, while maturation refers to the tempo and timing of progress towards the mature biological state. The variation in the progress over time implies variation in the rate of change. In this review maturation refers to the biological process unless mentioned otherwise.

Within the growth and maturation research several methods have been used to establish the biological maturation. By establishing the maturity status and the onset of maturation, an estimate can be made of a player being early, on-time, or delayed in maturation. The maturation in childhood and adolescence is usually viewed in the context of three types of indicators: Skeletal, Sexual or Somatic (Malina et al., 2004a). Of these three types only 
skeletal age can be used in both childhood and adolescence. However, it is probably the most costly and time consuming method (Malina et al., 2007a).

The estimation of skeletal age involves the matching of bone $x$-rays with a reference sample and provides valid and reliable indication of the status of the maturation process (Malina et al., 2004a; Malina et al., 2007a). In most cases a hand-wrist radiograph is matched to a set of criteria. As can be seen in table I, the Tanner-Whitehouse and the Fels method are most frequently used in soccer research. When Skeletal Age (SA) is estimated it can be compared to the Chronological Age (CA) to establish if an adolescent is early, on-time, or delayed in his/her skeletal maturity (Malina et al., 2004a; Malina et al., 2007a).

During adolescence the assessment of sexual maturity is a useful indicator of maturation. For boys these include the development of pubic hair, genitals and to a lesser extent hormone levels. Pubic hair and genital development are rated relative to the criteria set by Tanner in 1962. The stages of Pubic Hair $(\mathrm{PH})$ and Genital $(\mathrm{G})$ development range from I (prepubertal) to 5 (post-pubertal) in which the $2^{\text {nd }}$ stage represents the first overt manifestation of characteristics. Although the stages for pubic hair and genital development are equivalent they should not be combined for an overall score. Rather, they are an indication of advancement in maturation (Malina et al., 2004a).

Somatic maturity refers to the timing of maximum growth during adolescence. The maximal gain in height, or grow spurt, is referred to as the Peak Height Velocity (PHV). Any study has to last at least 5 years after which the PHV can be mathematically derived (Philippaerts et al., 2006). Percentage of attained adult stature is another somatic indication of maturation. The adolescents who are closer to their (predicted) adult stature in the same age group are more advanced in maturation (Malina et al., 2004a).

Table I. Overview of reviewed maturation studies in soccer payers

\begin{tabular}{|c|c|c|c|c|c|}
\hline $\begin{array}{c}\text { Type of } \\
\text { predictors in the } \\
\text { study }\end{array}$ & & $\mathrm{N}^{*}$ & $\begin{array}{c}\text { Maturation } \\
\text { assessment } \\
\text { method }\end{array}$ & $\begin{array}{c}\text { Maturity } \\
\text { status }\end{array}$ & $\begin{array}{l}\text { Aspects of } \\
\text { Predictors } \\
\text { *** }\end{array}$ \\
\hline \multirow[t]{2}{*}{ Physical } & Malina 2000 & $\begin{array}{l}\text { Portugal, elite, } \\
n=135,10.7- \\
16.5 \mathrm{yr}\end{array}$ & SA: Fels method & $\begin{array}{l}38,5 \% \text { vs. } \\
11,85 \%{ }^{2}\end{array}$ & A \\
\hline & $\begin{array}{l}\text { Hansen } \\
\text { 1999a }\end{array}$ & $\begin{array}{l}\text { Copenhagen } \\
\text { area, elite } \times \\
\text { local, } n=98, \\
\text { 10.5-13.0 yr }\end{array}$ & $\begin{array}{l}\text { Testicular } \\
\text { Volume and } \\
\text { Testosterone }\end{array}$ & & $A$ \\
\hline
\end{tabular}

(continues) 


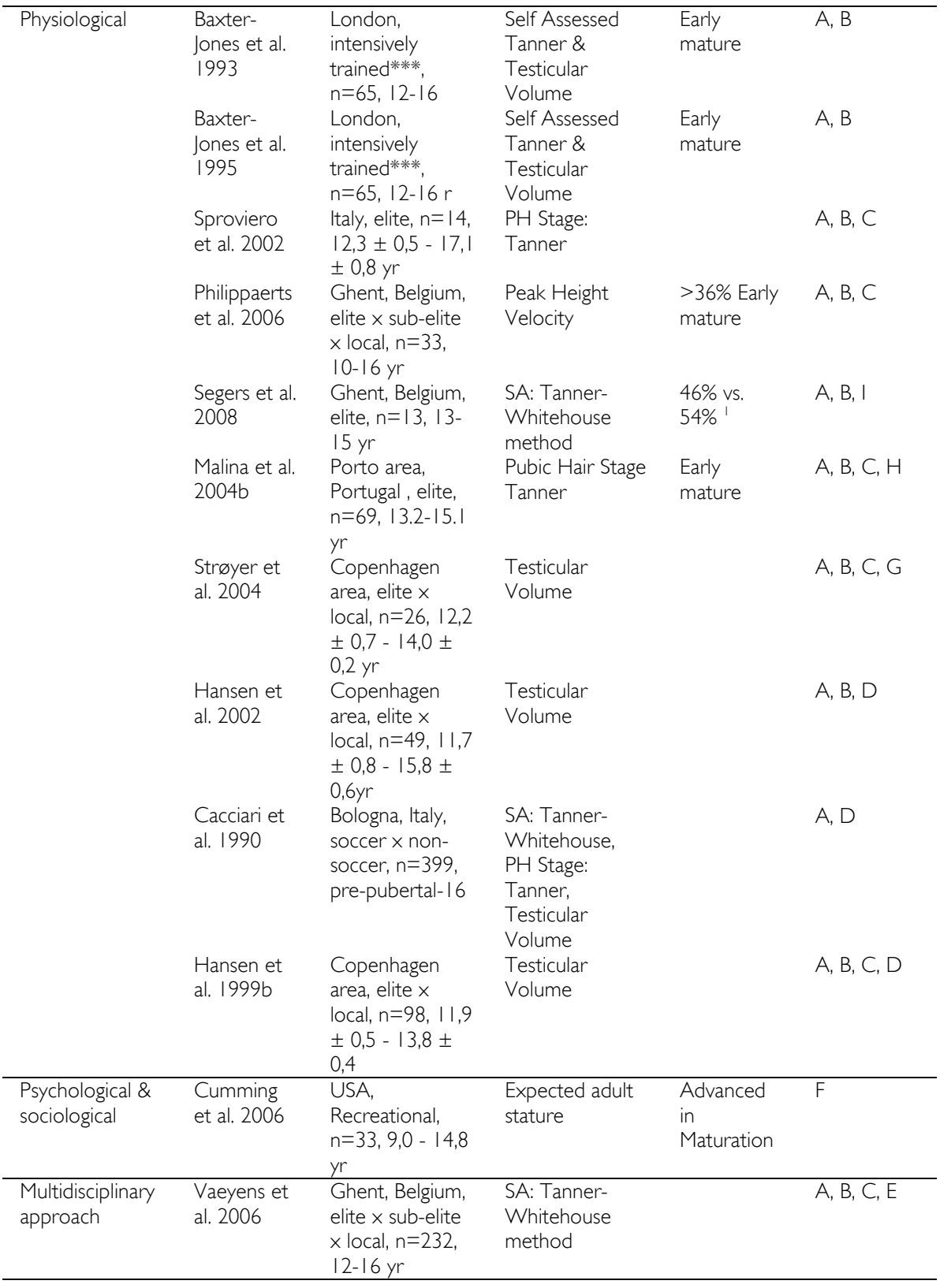

Notes: [*] Male players only. [**] Aspects of potential predictors: (A) Physical; (B) Aerobe; (C) Anaerobe/strength; (D) Hormonal; (E) Skill; (F) Psycho-social; (G) time-motion; (H) position; (I) Biomechanics. [****] Comparison between different sports. (I): Controlled percentage early vs. late maturing players. (2): Early vs. Late maturing players. [SA] Skeletal Age, [PH] Pubic Hair, [GYSP] Ghent Youth Soccer Project 
$\underline{\text { Reviewed studies }}$

a) Studies on physical predictors

Malina et al. (2000) assessed the anthropometrical characteristics and maturity status in a cross-sectional study of elite Portuguese adolescent players. A total of 135 players were tested who all played at the highest level in the Portuguese league in their age group. Of the 135 players 19 also played for the national team. The age ranged from 10,7 to 16,5 years (yr). Maturity status was estimated by means of skeletal maturity using the Fels method. No control group was included. Of the 135 players $38,5 \%$ was considered early mature or mature within their age group compared to chronological age. In contrast only I I,85\% was considered late mature. When it comes to playing position of national team members, forwards were the most ahead of chronological age $(1,2 \pm 0,4 \mathrm{yr})$ followed by defenders $(1,0 \pm 0,4 \mathrm{yr})$ and midfielders $(0,5 \pm 0,5 \mathrm{yr})$. The data suggested that, with age and presumably experience, boys advanced in skeletal maturation dominate soccer.

In a short longitudinal study by Hansen et al. (1999a) the relationship of maturation with the differences in anthropometrical characteristics were evaluated. All 98 elite and non-elite adolescent players (age: 10,5 - 13 yr) participated at the highest level in their age group in the Copenhagen area. The first ranked teams in the competition were classified as elite and the lowest ranked teams as non-elite. No control group was included and no aspects concerning the players' position were mentioned. Maturation was estimated with testicular volume. Elite teams were significantly older than nonelite teams. Elite teams were also found to be significantly more mature even when adjusted for age. Elite teams were heavier, taller and had lower fat percentages. Values for serum testosterone and insulin-like-growth factor were higher for elite compared to non-elite players.

\section{b) Studies on physiological predictors}

Two of the evaluated papers made a comparison between soccer, swimming, tennis, and gymnastics in a mixed-longitudinal study on the development of physiological characteristics. Both papers were written by Baxter-Jones et al. (1993 and 1995) and consisted of the same 453 participants from the London area, both male and female. For the soccer population only males were included and no control group was used. The age of the 65 soccer participants was 12 to 16 years. The soccer population was reported to be intensively trained with about 13 training hours per week. However, no distinction was made in a player's position. Maturation was estimated with testicular volume 
and self assessed sexual maturity in Tanner stages. Soccer players reported to be less mature than swimmers and tennis players and more mature than gymnasts. Twenty-seven of the sixty-five soccer players were on average $13,7 \pm 0,9$ years in Tanner stage 2 to 3 . The average $\mathrm{VO}_{2}$-max was $55,7 \pm 3,7$

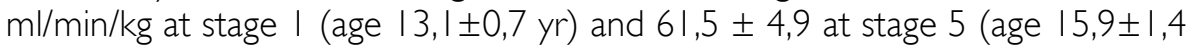
yr) (Baxter-Jones et al., 1993). Aerobic power was found to be significantly related to pubertal development. The athletes in sports in which large physiques were necessary for performance (e.g., swimming, soccer and tennis) tended to be advanced in sexual maturation (Baxter-Jones et al., 1995).

Sproviero et al. (2002) studied the longitudinal effects of maturation on the physiology of 14 well trained adolescent soccer players. They were classified as elite and played at a professional Italian soccer club. The age at the first test was between $12,3 \pm 0,5$ and $15, \mid \pm 0,8$ years, and at second test players were between $14,3 \pm 0,3$ and $17,1 \pm 0,8$ years. No control group was included. Besides the exclusion of goalkeepers no differences in playing position were mentioned. Sexual maturation was assessed using Tanner pubic hair stages. No comparison was made when it comes to the onset of maturation. The anthropometrical growth corresponded to the change in the level of maturation. Furthermore, the aerobic capacity in $\mathrm{ml} / \mathrm{kg} / \mathrm{min}$ showed a significant increase corresponding to the transition period from Tanner stage 2 to $3-4$, e.g., $60,01 \pm 5,1 \mathrm{ml} / \mathrm{kg} / \mathrm{min}$ and $67,3 \pm 4,6 \mathrm{ml} / \mathrm{kg} / \mathrm{min}$ respectively. The same relation was found for anaerobe muscle power. In the later Tanner stages (4 and 5) the increase was still significant for anaerobe muscle power but not for aerobe capacity.

The grow spurt is a well known phenomenon in adolescence. Philippaerts et al. (2006) investigated the relationship between peak height velocity and physical performance in a mixed-longitudinal study for 33 adolescent soccer players ( $13-16$ yr). In addition to the included 33 players, 25 players were excluded because of reaching PHV before the beginning of the study suggesting early maturation. They had a chronological age of $12,12,6 \pm 0,5$ years and a skeletal age of 13,5 1,2 years. The study included elite( 6 training hours per week), sub-elite (4 training hours per week) and non-elite (3 training hours per week) without making reference of player positions or using a control group. Maturity was assessed with skeletal age (Tanner-Whitehouse) and PHV. The 33 players were selected from the Ghent Youth Soccer Project, Belgium, and had a mean age at PHV of $13,8 \pm 0,8$ years. Age at Peak weight velocity was the same. Running speed attained maximal growth just before $\mathrm{PHV}$, and maximal aerobic power reached maximal growth coinciding with $\mathrm{PHV}$. During PHV the greatest gain was found in muscular strength, balance, speed of limb movement, trunk strength, upper-body muscular endurance, explosive strength and power. Trends of gain in muscular strength and power remain after peak height velocity. 
Segers et al. (2008) did a systematic research on running economy.

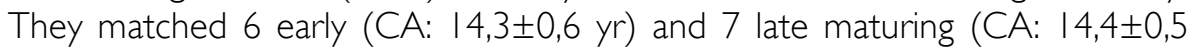
yr) adolescent soccer players. The subjects were all participant in the previous mentioned mixed-longitudinal study: Ghent Youth Soccer Project. They practised at least 4,5 hours/week. There was no comparison with a control group or mentioning of player position differences. The skeletal age of the 13 participants was assessed using the Tanner-Whitehouse system. Early and late matures did not significantly differ in age but early maturing players were significantly taller, heaver, stronger and had a higher absolute $\mathrm{VO}_{2}$-max $(3,84 \pm$ 0,5 vs. 2,57 $\pm 0,4 \mathrm{l} / \mathrm{min}$ ). However when compensated for body weight the difference in $\mathrm{VO}_{2}$-max is not significant $(57,19 \pm 3,58$ vs. $57,63 \pm 5,58$ $\mathrm{ml} /$ leanbodymass $1,058 / \mathrm{min})$. The study found no difference in running economy between early and late matures.

The objective of a cross-sectional study by Malina et al. (2004b) was to estimate the contribution of experience, body size and maturity status to variation in the functional capacity of 69 soccer players between 13,2 and I5, I years. No control group was used to compare the soccer population to the non-soccer population. The elite players competed at the highest level in their age group in the Portuguese first division. Sexual maturation was attained using the $\mathrm{PH}$ stage method. Of these 69 players, 19 players were biological mature $(\mathrm{PH}$ stage 5$)$ and 21 players were almost mature $(\mathrm{PH}$ stage 4$)$. Furthermore, $45 \%$ of players 13,2 to 13,9 years of age and $64 \% 14,0$ to 15,1 years of age were in $\mathrm{PH}$ stages 4 and 5 . The distribution of stages of pubic hair suggested that they were advanced in maturation. When it comes to the position of the player, on average, midfielders scored highest on aerobic capacity but lowest in speed and power whereas forwards and defenders were quite similar in speed and power. While forwards were significantly older, $70 \%$ of the forwards and defenders was in pubic hair stage 4 or 5 which suggested that as a group they were in advance of midfielders in maturity status. When controlled for age, height and weight advanced maturation was associated with better aerobe resistance and anaerobe capacity and power. Stage of maturity and years of training in soccer accounted for $21 \%$ of the variance in aerobic capacity while weight and stage of maturity accounted for $50 \%$ of the variance in anaerobic sprinting capacity. The stage of maturity, together with height accounted for $41 \%$ of the variance in anaerobic power.

The physiological demands and activity pattern of a match have been mapped for different maturational stages by Strøyer et al. (2004). Twenty-six adolescent players from the three most successful clubs in the Copenhagen area, Denmark, were recruited. Age, maturation, and the ranking of their team in the competition divided the participants in three groups, ten non-elite $(12,2 \pm 0,7 \mathrm{yr})$ and nine elite players $(12,6 \pm 0,6 \mathrm{yr})$ at the beginning of 
adolescence, and seven elite players $(14,0 \pm 0,2)$ at the end of adolescence. No control group was used and no distinction was made in player positions. Maturation was estimated by measurement of testicular volume. No mentioning was made about timing of the onset of maturation in the groups, although reaching the end of maturational development at age 14 was considered early mature (Malina et al., 2004a). The absolute $\mathrm{VO}_{2}$-max was not significantly different at the beginning of adolescence for the elite and nonelite. However $\mathrm{VO}_{2}$-max did increase with maturation for the elite towards the end of adolescence $(2,47 \pm 2,8$ vs. $3,59 \pm 4,4 \mathrm{l} / \mathrm{min})$. When adjusted for body weight the difference was not significant (58,6 $\pm 5,0$ vs. $63,7 \pm 8,5$ $\mathrm{ml} / \mathrm{kg} / \mathrm{min}$ ). For elite players the maximum heart rate did not significantly change during adolescence but the rest heart rate was significantly lower for the older group $(66,5 \pm 5,1 \mathrm{bpm}$ vs. $57,1 \pm 3,7 \mathrm{bpm})$. The exercise level during match play and $\mathrm{VO}_{2}$-max tended to be higher for the midfielders/attackers compared to the defenders, with differences increasing with age. Maturation was found to have no significant effect on relative aerobic load and relative HR for elite players.

The aim of a longitudinal study by Hansen and Klausen (2002) was to evaluate the development in aerobic power in elite as well as non-elite Danish adolescent soccer players, and to relate it to maturation, haemoglobin and hematocrit levels. No control group was used or distinction in playing positions. The maturation of all forty-nine subjects ( $10-16 \mathrm{yr}$ ) was assessed using the testosterone levels and testicular volume. The status of elite (2I) and non-elite (28) were based on the ranking of their team in the highest level of competition. The elite players were significantly older and more mature. The advanced maturity is consistent when elite and non-elite were matched by chronological age suggesting earlier maturation in the elite group. Moreover, elite players had steeper increase in $\mathrm{VO}_{2}$-max and higher $\mathrm{VO}_{2}$-max values throughout the adolescent period, both absolute and when adjusted for weight. Furthermore, a relationship was found between maturation, haemoglobin concentrations as well as with the development of aerobic power.

Cacciari et al. (1990) investigated the effects of soccer on anthropometrical and hormonal aspects of growth. The 399 Italian boys who participated in this cross-sectional study consisted of two groups. 175 Participants played competitive soccer (4-14 hours/week) and the control group of 224 participants had never performed regular sporting activities. No mentioning was made of players' position. The participants were classified as pre-pubertal (testicular volume lower than 2,5 ml) or pubertal (age 10-16). For estimating maturation skeletal age, $\mathrm{PH}$ and testicular volume were used. The football players were significantly more mature then the controls in all

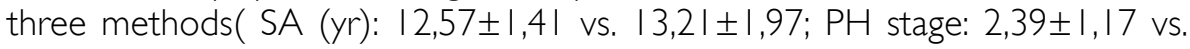




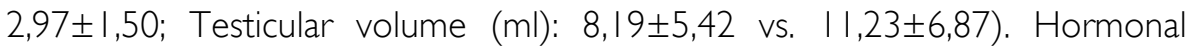
levels (Cortisol, testosterone and DHEA-S) were significantly higher in football players compared to controls and correlated positive with all somatic growth indicators (e.g., weight and height).

To examine the development of muscle strength in relation to training and testosterone in adolescence, Hansen et al. (1999b) did a longitudinal study on 98 Danish adolescent soccer players (II-I4 yr) of which 48 were elite. Elite and non-elite was classified in the same way as the studies by Hansen et al. (1999a), Hansen and Klausen (2002) and Strøyer et al. (2004). No control group was used nor were playing positions included. Once again, elite players were older, taller, stronger and more mature compared to nonelite players; even when adjusted for chronological age. No regard was given to the onset of maturation. Elite and non-elite players had a similar increase in testosterone levels across adolescence with elite players scoring consistently higher on aerobe capacity. Furthermore, testosterone had a positive relationship with strength development.

\section{c) Studies on psychological predictors}

The cross-sectional studies by Malina et al. (2005) and Malina et al. (2007), were both on sport specific skill characteristics in adolescent soccer players aged 13,2-15, I years. Both studies, together with the study by Malina et al. (2004b), used the same sample of 69 adolescent soccer players. The subjects were elite and played at the highest level in the Portuguese division. No control group was included in the studies. Stage of pubic hair was used to asses the maturity status. The onset of maturation was reported earlier in this review in the study by Malina et al. (2004b).

The aim of the study done by Malina et al. (2005) was to estimate the contribution of experience, body size and maturity status to the variation in sport specific skills. There was considerable variation in the scores of the skill tests, but none of the scores grouped by player positions were significant. Although there was a trend of better scores on the skill test for increasing maturity status, it was only significant for the dribbling speed test. This significant result persisted when age, height and body mass were used as covariates. The stage of maturity and years of training accounted for $13 \%$ of the variance in the ball control test with the body. Maturity, height, and height*body mass interaction accounted for $14 \%$ of the variance in ball control test with the head. Age and maturity stage accounted for $21 \%$ of the variance in the test requiring dribbling speed. Even though the contributions were small, the results suggested that advanced biological maturity status was associated with better performance on four skill tests. 
The second study, done by Malina et al. (2007) described the characteristics of adolescent soccer players grouped by skill level. A total of 12 of I 4 players in the highest skill quintile and II of the 14 players in the high skill quintile were in $\mathrm{PH}$ stages 4 or 5 . Although the highest quintile was on average half a year older then the lowest the trend suggested that advanced maturity status was coherent with high skill scores. All skill quintile were equally represented in defenders and midfielders. The forwards were centred around the middle three quintiles. Furthermore, maturity (positive) and height (negative) together accounted for $21 \%$ of the variance in the combined skill score.

\section{d) Studies on sociological predictors}

Cumming et al. (2006) examined, cross-sectional, the relationship between maturity status, Body Mass Index, age and perception of autonomy support in 70 north-American participants of which 43 were male $(9,0-14,8 \mathrm{yr})$. No distinction was made in position on the field nor was a control group included. The mean number of years participants competed in recreational soccer was $5,1 \pm 1,9 \mathrm{yr}$. Maturity status was assessed by a participants' predicted adult stature. The players were classified as advanced in maturity status. Maturity status significantly predicted $18 \%$ of the variance in the autonomy support from the coach. All other variables were found not to be significant.

\section{e) Studies with a multidisciplinary approach}

Talent research in soccer should take on a multidisciplinary approach as discussed earlier in the results. A study by Vaeyens et al. (2006) assessed anthropometry, functional capacity, and sport specific skills as well as maturity status of elite, sub-elite and non-elite players. Participants were grouped according to playing level: Elite (first or second division); sub-elite (third or fourth division), and non-elite (regional division). No control group was included. A mixed-longitudinal sample of 232 Belgium players was tested annually over 5 consecutive years. Participants ( $12-16$ yr) were enrolled in the earlier mentioned Ghent Youth Soccer Project and were grouped in one year chronological age categories. Furthermore, goalkeepers were excluded, limiting the analyses to defenders, midfielders and forwards. Skeletal age was assessed with the Tanner-Whitehouse method. Although there was no mentioning of the onset of maturation the results showed that maturity affected anthropometry in all age groups. Maturation also significantly affected strength, power and flexibility in de under 14 and under 15 players. Additionally, maturation affected sprint speed and cardio respiratory endurance in the under 15 and 16 age group. Sport specific skill was only significantly affected in the under 14 group. 


\section{DISCUSSION}

The aim of this literature based review was to asses the effects of maturation on potential predictors of talent in the soccer population within a multidisciplinary approach. In total 16 studies met the criteria and have been reviewed. Two studies were specifically designed to measure the effects of maturation on physical predictors, nevertheless physical aspects and maturation were also discussed in other studies. Ten of the sixteen reviewed studies were on the effects of maturation on physiological predictors, two concerned the maturational effects on psychological and cognitive skills and only one the effect on sociological predictors. However, there is an overlap in the last three mentioned studies. Finally, one study was discussed with regard to a multidisciplinary approach and maturation effects in soccer. As can be seen in table I, some of the studies used either the same participants or are a selection of the larger coordinated study. Accordingly, some caution is needed with the interpretation of the results.

Although research suggests that the physical characteristics of young players are related to performance, many of the physical qualities that distinct elite from sub-elite may not be noticeable until full adulthood is reached (Williams et al, 2000b). Research by Cacciare et al. (1990) suggests that soccer does not have a significant influence on an individual's definitive physical development, established genetically. Young athletes, as soccer players, grow in a similar manner as non-athletes and much of the variation in body size is associated with the variation in the rate of maturation (Malina et al., 2004a). However, soccer might affect the onset of adolescence (Cacciari et al., 1990). Philippaerts et al. (2006) reported a main gain in height, or grow spurt, or Peak Height Velocity (PHV) in the elite soccer population at age 13,8 \pm 0,8 Years. The age of Peak Weight Velocity (PWV) was found to be identical. However, twenty-five participants were not included in this research because they had already reached PHV and had a SA more than one year ahead of $C A$, suggesting early maturation. Research in the general population reported PHV to occur at age 14.I \pm 0.9 years (Beunen et al., 2000). Although the age at which PHV is reached in soccer is not far from that of the normal population, the trend is towards early maturation in soccer. Running speed attains maximal growth just before $\mathrm{PHV}$, and maximal aerobic power reaches maximal growth coinciding with PHV. During PHV the greatest gain was found in muscular strength, balance, speed of limb movement, trunk strength, upperbody muscular endurance, explosive strength, and power (Naughton et al., 2000; Philippaerts et al., 2006). This is most probably related to the spurt in muscle mass during adolescence that occurs shortly after PHV. Trends of gain in muscular strength and power remain after PHV and might also reflect an influence of the training effect (Naughton et al., 2000; Philippaerts et al., 2006; 
Yague et al., 1998). The maximum gain in power in the adolescent elite soccer population lies at PHV whereas in the general adolescent population the maximum gain in power is closer to PWV. The small differences might lie in the overlapping of PHV and PWV in elite adolescent soccer players rather than PWV following PHV as is the case in non-athletes (Geithner et al., 2004; Malina et al., 2004a).

Regarding the positions of the players on the field, forwards and defenders tend to be more advanced in sexual maturation than midfielders. In the ages 14 through 16, Malina (2004) found an over representation of the later adolescent stages $\mathrm{PH} 4$ and $\mathrm{PH} 5$ in forwards and defenders. This is in contrast to midfielders in which all five stages were equally represented. Forwards and defenders are reported to be advanced in skeletal age compared to chronological age by $1,2 \pm 0,4$ years and $1,0 \pm 0,4$ years respectively. Midfielders were, on average, advanced in skeletal age by $0,5 \pm 0,5$ years (Malina et al., 2004b; Malina et al., 2000). Malina et al. (2004b) reported that midfielders score highest on aerobic resistance but lowest in speed and power. Forwards scored slightly higher in speed and power compared to defenders, but scored lowest on aerobic resistance. When aerobic capacity, speed and power are viewed by pubic hair stages they increased with maturation. The trends were most noticeable in aerobic capacity and speed and to a lesser extent in power. Furthermore, it is suggested that this age and maturity associated variation might reflect the specific size demands of different playing positions (Malina et al., 2000; Malina et al., 2004b).

As with the normal population, the physiological capacity in the elite adolescent soccer population increases with biological and chronological age (Hansen et al., 2002; Malina et al., 2007b; Strøyer et al., 2004). A progressive increase in absolute aerobic power through the pre- mid- and late adolescent years is confirmed by several studies (Naughton et al., 2000; 1025; Malina et al., 2007b; Malina et al., 2004b; Mota et al., 2002). When considering the known difference in aerobic capacity between the trained and the untrained population, young elite soccer players show higher absolute aerobic capacity values compared to the normal population on the later maturational stages (Baxter-Jones et al., 1993). There seems to be almost no difference in $\mathrm{VO}_{2-}$ max between the non-elite and the elite players in the beginning of adolescence (Hansen et al., 2002; Strøyer et al., 2004). However when comparing elite and non-elite adolescent soccer players, elite players seem to have higher and steeper increase in $\mathrm{VO}_{2}$-max values compared to non-elite players (Hansen et al., 2002). Furthermore, it has been suggested that the degree of maturation influences $\mathrm{VO}_{2}$-max through its close association with weight, muscle mass and haemoglobin concentrations together with an increasing influence of the training effect (Armstrong et al., $200 \mathrm{la}$; Hansen et al., 2002). In general, growth in aerobic power was found significantly related 
to physical growth (age, height, and weight) and to pubertal development (Baxter-Jones et al., 1993; Mota et al., 2002; Naughton et al., 2000).

Although many studies have come to the conclusion that the $\mathrm{VO}_{2}$ consumption and thus aerobe capacity was affected by the increase in body weight during maturation, there is no agreement to what extent absolute $\mathrm{VO}_{2}$-max consumption should be corrected for body weight during maturation. Italian research found that $\mathrm{VO}_{2}$-max increases with biological maturation after compensating for body mass (Sproviero et al., 2002). Soccer players at age 12,3 $\pm 0,5$ in Tanner stages $1 \& 2$ increased significantly in $\mathrm{VO}_{2}-$ max when reaching age $14,3 \pm 0,3$ in Tanner stages $3 \& 4(60,01 \pm 5,1$ vs. $67,3 \pm 4,6 \mathrm{ml} / \mathrm{kg} / \mathrm{min}$ ). This is confirmed by results in Denmark. Elite adolescent players did increase significantly in absolute $\mathrm{VO}_{2}$-max within the same age range as in the Italian study $(2,47 \pm 2,8$ vs. $3,59 \pm 4,4 \mathrm{I} / \mathrm{min})$ but although a trend can be seen in the increase in $\mathrm{VO}_{2}$-max when compensated for body weight, it was not significant (58,6 $\pm 5,0$ vs. $63,7 \pm 8,5 \mathrm{ml} / \mathrm{kg} / \mathrm{min}$ ) (Strøyer et al., 2004). When comparing early and late matures within one age group Armstrong et al. (1999) and Segers et al. (2008) found that the difference in the $\mathrm{VO}_{2}$ consumption is not dependent on maturation when it is compensated for body weight. This is in accordance with research done in the Ghent Youth Soccer Project. The differences in absolute $\mathrm{VO}_{2}$ at age 14 is significant between early and late matures (3,84 $\pm 0,5$ vs. 2,57 $\pm 0,4 \mathrm{l} / \mathrm{min}$ ) but not when compensated for body weight $(57,19 \pm 3,58$ vs. 57,63 $\pm 5,58$ $\mathrm{ml} /$ leanbodymass $1,058 / \mathrm{min}$ ). These inconsistencies might be the result of the way of scaling $\mathrm{VO}_{2}$-max and body weight. This is either done by calculating $\mathrm{VO}_{2}$ consumption per $\mathrm{kg}$ body weight or by using an allometric approach by calculating $\mathrm{VO}_{2}$ per $\mathrm{kg}$ body weight multiplied by a scaling factor (Armstrong et al., 1999; Segers et al., 2008). Moreover, not all studies use the same calculations, for example body weight in lean body mass or in total body weight. Maturation alters the effects of body size and this should be taken into account when interpreting the results of physical performance tests (Armstrong et al., 1999; Nedeljkovic et al., 2007).

A matter closely associated with aerobic capacity, and therefore also important in soccer, is running technique. Although it is suggested that running economy is influenced by maturation, research shows otherwise. A study among Belgian boys shows that maturation seems to have no effect on running economy in elite adolescent soccer players (Segers et al., 2008). When early and late matures were compared, the cardiovascular capacity was relatively the same when adjusted for lean body mass and cannot be the cause for lack of difference in running economy (Philippaerts et al., 2006; Segers et al., 2008). It is suggested that while absolute stride length between early and late matures was the same and late matures have shorter legs, a relatively larger stride length enables less mature players to run with the same running 
economy (Segers et al., 2008). There seem to be no significant differences within an elite soccer population but their might be a difference between elite and non-elite adolescent players. Although Danish pre-pubertal and pubertal elite players of age 12 showed relatively better values when it comes to running economy and $V_{2}$-max compared to their non-elite peers the differences were not statistically significant (Strøyer et al., 2004). In general it can be concluded that maturation facilitates an increase in absolute aerobe capacity, to what extent this increase is necessary, or caused by a larger physique remains a matter of discussion. Fact is that it enables a player to perform at a higher level (Armstrong et al., 1999; Naughton et al., 2000).

An average child has about $30 \%$ of the anaerobic power of a 20 -year adult (Van Praagh et al., 2002). However elite adolescent soccer players exhibit higher peak anaerobic power outputs during all adolescent stages than their sedentary peers, in particular in the stages 3 to 5 (Vaeyens et al., 2006). This difference is most likely caused by the training effect. The maximal muscle power is related to cross-section of the muscles involved in the exercise ( $V a n$ Praagh et al., 2002). But even when scanned for body dimensions like relative strength and maximal oxygen uptake, early matures seem to have an advantage over late matures (Segers et al., 2008). When anaerobic power is expressed relative to body weight it becomes apparent that it increases most in the $2^{\text {nd }}, 3^{\text {rd }}$ and $4^{\text {th }}$ pubic stage (Sproviero et al., 2002). This is in agreement with research among adolescent soccer players 13-15 years of age. Sexual maturation significantly contributed to the explained variance on anaerobic capacity (e.g. sprint and vertical jump ability) (Malina et al., 2004b). In research by Hansen (1999b) the development of isometric strength and performance in broad jump was related body size but also to changes in serum testosterone concentrations, indicating that testosterone is important for development of strength in young boys. However, elite players were stronger than non-elite players independent of testosterone concentration, also with correction for body size, indicating that other factors associated with being elite also effect the development of strength. Values of testosterone levels are higher for pubertal and lower for pre-pubertal soccer players than the general population. Research concluded that testosterone was important in strength development for boys (Hansen et al., 1999b). It is assumed that the higher values in adolescent subjects were justified by them being more sexually developed than the controls, while in pre-pubertal subjects the effects of the intensity of training prevailed, causing a decrease in plasma testosterone, as in adult athletes (Cacciari et al., 1990). Thus it seems like the difference in power is mostly caused by the training effect but maturation plays a fundamental role in the onset of development and trainability of anaerobic power and capacity ( Armstrong et al., $200 \mathrm{lb}$; Hansen et al., 1999b; Naughton et al., 2000). 
The impact of biological growth and maturation on psychological and social development of young athletes has received relatively little attention (Cumming et al., 2006). The lacking of research on the effects of maturation on personality, in the adolescent soccer population, provides an indication that this has received even less attention. The physical changes associated with growth and maturation and the changes and growth of the brain may have a profound impact upon the technical skills, self-perception, motives, beliefs, and ultimately, behaviour of young athletes (Cumming et al., 2006; Malina et al., 2005; Van-Yperen et al., 1999).

Although there is no consent about how much the maturation contributes to the development of technical skills, it is associated with better technical performance on several skill tasks like dribbling, ball control and shooting (Malina et al., 2005; Malina et al., 2007b). Malina et al. (2005) found a general trend in better performance on skill tests continuing into sexual maturation. However, this was only significant for a dribbling test with pass. In their analyses maturity explained between 10 and $20 \%$ of the variance on different technical performance tasks. Malina et al. (2007) also found that aerobic resistance and maturity status together explained a significant amount of the variance in the skill score of 14 year old elite soccer players. This was confirmed in other age groups by research from Vaeyens et al. (2006). They showed that difference in maturity status influenced technical skills in elite adolescent players and it was most apparent at the age of 14. As such, advanced maturity status is associated with better skills. This might also reflect the positive influence of maturation on earlier mentioned components in adolescent boys (e.g., strength, speed and power) which are closely related with technical skills. The effect of maturation on technical skills is also influenced by the maturational changes in the central nervous system. This affects the neural control and perceptual-cognitive skills such as anticipation and visual search strategies (Williams, 2000, Williams et al, 2000b, Malina et al., 2005).

Cumming et al. (2006) suggest that the 'mediated effects model of adaptation' provides an appropriate theoretical framework from which to examine the psychological and social significance of maturation in adolescent soccer. How an individual adjusts socially and psychologically to changes associated with maturation and growth depends on his or her ideation about his or her biological changes and the subjective meaning or affective significance attributed to them. Psychological and behavioural effects are mediated by internalized psychological factors like body image, self-esteem, self-perception and evaluation, beliefs, and mind-sets on body development. The effects are presumably moderated by exogenous or contextual factors as socio-cultural contexts, ideals, practice, and expectations by coaches or parents. Significant others (coaches and parents) tend to evaluate biologically 
early mature males as socially better adjusted, having a better physiques, and better physiological abilities compared to their later maturing peers (Cumming et al., 2006).

In general it is assumed that progression in maturation coincides with more autonomy support because physically better suited players (early matures) have greater potential for success and require less supervision. But contrary to this expectation Cumming et al. (2006) found that advanced maturity status was associated with lower perception of autonomy support from coaches. So instead of experiencing less autonomy as controlling and reducing intrinsic motivation, elite soccer players might perceive less autonomy as more informational and thus prosper.

There is a substantial lack of research when it comes to the development of psychological characteristics in the context of sexual/biological maturation and (elite) soccer. Furthermore, identified psychological characteristics that are important in elite adult soccer are sometimes assumed to be present in some form in the elite adolescent player. Those who posses and retain these characteristics may have a higher chance of developing into an elite professional players (Morris et al., 2000). But there is no hard evidence that the variables which are important for success in adolescence are the same as in adulthood. In addition, there is hardly any evidence that important psychological traits remain stable in the transition from adolescence into adulthood (Morris et al., 2000; Patton et al., 2007). So once again one should be cautious with interpreting these results. Relatively little is still known about the effects of maturation on psychological aspects of adolescent soccer players.

In the introduction the Relative Age Effect was mentioned. This overrepresentation of players born in the first quarter of the selection year was based on the physiological advantages of the more biologically mature players. In the discussed research in this review, this phenomenon is confirmed (Baxter-Jones et al., 1993; Baxter-Jones et al., 1995; Cumming et al., 2006; Malina et al., 2000; Malina et al., 2004b; Malina et al., 2005; Malina et al., 2007; Philippaerts et al., 2006; Segers et al., 2008). The selection bias present in the relative age effect can also be witnessed in the effects of maturation, a so called "Relative Maturation Effect". Therefore, it is of importance for the selection process to take maturation into account. Potential talent may perhaps be overlooked because of inferior physiological performance as a consequence of being late in the maturing process. On the other hand, this might raise an ethical question. Should coaches keep the early mature and physiological strong player, who is considered to be of inferior potential and not elite worthy, to be kept in the academy to raise the performance level and facilitate the development of the late maturing talented player? 
In summary, elite adolescent soccer player develop in a similar way as the normal population. Maturation seems to have no effect on the definitive stature established genetically but it does have a significant effect on the development of physical predictors of elite adolescent soccer players towards an elite adult physique. Physiological predictors are affected as well. Maturation facilitates an increase in absolute aerobe power and capacity and plays a fundamental role in the onset of development and trainability of anaerobic power and capacity. With regard to the psychological predictors, not much is known about the effects of maturation on the perceptual-cognitive skills in soccer. However, maturation seems to have a positive effect on the development of technical skills. The research on sociological predictors within the soccer population is rather scarce. When taking the high potential discriminative power of psychological and sociological predictors into consideration, this will need to receive significantly more attention in further research. Furthermore, maturation has to be taken into account when scouting and evaluating talent in soccer.

\section{REFERENCES}

Armstrong N, Welsman JR (200la). Peak oxygen uptake in relation to Growth and maturation in II- 17 yr old humans. European Journal of Applied Physiology, 85: 546551

Armstrong N, Welsman JR, Chia MYH (200 Ib). Short term power output in relation to growth and maturation. British Journal of Sports Medicine, 35: I I 8- 124

Armstrong N, Welsman JR, Kirby BJ (1997). Sub-maximal Exercise and maturation in |2-year-olds. Journal of Sports Sciences, 17: 107-1 14

Armstrong N, Welsman JR, Nevill AM, Kirby BJ (1999). Modelling growth and maturation changes in peak oxygen uptake in 11-13 yr olds. Journal of Applied Physiology, 87: 2230-2236

Bangsbo J (1994). Energy demands in competitive soccer. Journal of Sports Sciences, 12 : s5-s 12

Baxter-Jones A, Goldstein H, Helms P (1993). The development of aerobic power in young athletes. Journal of Applied Physiology, 75(3): I I60-I I 67

Baxter-Jones ADG, Helms P, Mafulli N, Baines-Preese JC, Preece M (1995). Growth and development of male gymnasts, swimmers, soccer and tennis players: a longitudinal study. Annals of Human Biology, 22(5): 381-394

Beunen G, Malina RM (2004). Growth and Biologic Maturation: Relevance to Athletic Performance. In: "Growth, Maturation, and Physical Activity, 2nd edition". Human Kinetics, USA.

Beunen ,G., Ostyn M, Simons J, Renson R, Claessens Al, vanden Eynde B, Lefevre J,Vanreusel B, Malina RM, van't Hof MA (1997). Development and tracking in fitness components: Leuven longitudinal study on lifestyle, fitness and health. International Journal of sports Medicine, |8: s |7|-178 
Beunen G, Thomis M, Aes HH, Loos R, Malina RM, Claessens AL, Vlietinck R (2000). Genetic variance of adolescent growth in stature. Annals of Human Biology, 27(2): 173- 186

Cacciari E, Mazzanti L, Tassinari D, Bergamasehi R, Magnani C, Zappulla F, Nanni G, Cobianchi C, Ghini T, Pini R, Tani G (1990). Effects of sport (football) on growth: axiological, anthropometric and hormonal aspects. European Journal of Applied Physiology, 61: 149-158

Cumming SP, Battista RA, Standage M, Ewing ME, Malina RM (2006). Estimated maturity status and perceptions of adult autonomy support in youth soccer players. Journal of Sports Sciences, 24( I0): 1039-1046

Geithner CA, Thomis MA, Eynde BV, Maes HHM, Loos RJF, Peeters M, Claessens ALM, Vlietninck R, Malina RM, Beunen GP (2004). Growth in peak aerobic power during adolescence. Medicine and Science in Sport and Exercise, 36(9): 16 I6-1624

Hansen L, Klausen K (2002). Development of aerobic power in pubescent male soccer players related to hematocrit, haemoglobin and maturation. Journal of Sports Medicine and Physical Fitness, 44: 21 9-223

Hansen L, Klausen K, Bangsbo J, Muller J (1999a). Short longitudinal study of boys playing soccer, Parental Height, Birth Weight and length, anthropometry, and pubertal maturation in elite and non-elite Players. Paediatric Exercise Science, II: 199-207

Hansen L, Bangsbo J, Twisk J, Klausen K (1999b). Development of muscle strength in relation to training level and testosterone in young male soccer players. Journal of Sports Medicine and Physical Fitness, 87: | |4|-1|47

Helsen WF, Winckel J, Williams AM (2005). The relative age effect in youth soccer across Europe. Journal of Sports Sciences, 23(6): 629-636

Lemmink KAPM, Visscher C, Lambert MI, Lamberts RP (2004). The interval shuttle run test for intermittent sport players: evaluation of reliability. Journal of Strength and Conditioning Research, 18: 67-73

Malina RM, Bouchard C Bar-Or $\bigcirc$ (2004a). Growth, Maturation, and Physical activity. Second edition. Human kinetics, USA.

Malina RM, Chamorro M, Serratosa L, Morate F (2007a). TW3 and Fels skeletal ages in elite youth soccer players. Annals of Human Biology, 34(2): 265-272

Malina RM, Cumming SP, Kontos AP, Eisenmann JC, Ribeiro B, Aroso J (2005). Maturity-associated variation in sport-specific skills of youth soccer players aged I 3- I 5 years. Journal of Sports Science, 23 (5): 5 I 5-522

Malina RM, Eisenmann JC, Cumming SP, Ribeiro B, Aroso J (2004b). Maturityassociated variation in the growth and functional capacities of youth football (soccer) players I3-I 5 years. European journal of Applied Physiology, 91: 555-562

Malina RM, Peña Reyes ME, Eisenmann JC, Horta L, Rodrigues J, Miller R (2000). Height, mass and skeletal maturity of elite Portuguese soccer players aged I I-16 years. Journal of Sports Sciences, 18: 685 - 693

Malina RM, Ribeiro B, Aroso J, Cumming JC (2007b). Characteristics of youth soccer players aged 13-15 years classified by skill level. British Journal of Sports Medicine, 4I: 290-295

Morris T (2000). Psychological characteristics and talent identification in soccer. Journal of Sports Sciences, 18: 715-726

Mota J, Guerra S, Leandro C, Pinto A, Ribeiro JC, Duarte JA (2002). Association of maturation, sex, and body fat in cardio respiratory fitness. American Journal of Human Biology, 14: 707-712 
Naughton G, Farpour-Lambert NJ, Carlson J, Bradney M, Van Praagh E (2000). Physiological issues surrounding the performance of adolescent athletes. Sports Medicine, 30(5): 309-325

Nedeljkovic A, Mirkov DM, Kukolj M, Ugarkovic D, Jaric S (2007). Effect of maturation on the relationship between physical performance and body size.. Journal of Strength and Conditioning Research, 2 I ( I): 245 -250

Patton GC, Viner R (2007). Pubertal transitions in health. The Lancet, 369: I I 30-39

Pearson DT, Naughton GA, Torode M (2006). Predictability of physiological testing and the role of maturation in talent Identification for adolescent team sports. Journal of Medicine and Science in Sport, 9: 277-287

Philippaerts RM, Vaeyens R, Janssens M, Van Renterghem B, Matthys D, Craen R, Bourgois J, Vrijens J, Beunen G, Malina RM (2006). The relationship between peak height velocity and physical performance in youth soccer players. Journal of Sports Sciences, 24(3): $221-230$

Reilly T, Bangsbo J, Franks A (2000a). Anthropometric and physiological predispositions for elite soccer. Journal of Sports Sciences, I 8: 669-683

Reilly T, Williams AM, Neville A, Franks A (2000b). A multidisciplinary approach to talent identification in soccer. Journal of Sports Sciences, I 8: 695-702

Segers V, De Clercq D, Janssens M, Bourgois J, Philippaerts R (2008). Running economy in early and late maturing youth soccer players does not differ. British Journal of Sports Medicine, 42: 289-294

Sproviero E, de Vito G, Felci U, Macaluso A, Marchettoni P (2002). Physiological Evaluation of elite young soccer players. Medicino dello Sport, 55: I 8 | - | 87

Strøyer J, Hansen L, Klausen K (2004). Physiological profile and activity pattern of young soccer players during match play. Medicine and Science in Sport and Exercise, 36(I): 168-174

Vaeyens R, Philippaerts RM, Malina RM (2005). The relative age effect in soccer: A match-related perspective. Journal of Sports Sciences, 23(7): 747-756

Vaeyens R, Malina RM, Janssens M, Van Renterghem B, Bourgois J, Vrijens J, Philippaerts RM (2006). A multidisciplinary selection model for youth soccer: the Ghent Youth Soccer Project. British Journal of Sports Medicine, 40: 928-934

Van Praagh E, Doré E (2002). Short-Term Muscle Power During Growth and Maturation. Sports Medicine, 32(I I): 701-728

Van-Yperen NW, Duda JL (1999). Goal orientations, beliefs about success, and performance improvement among young elite Dutch soccer players. Scandinavian Journal of Medicine \& Science in Sports, 9: 358-364

Williams AM (2000). Perceptual skil in soccer: implications for talent identification and development. Journal of Sports Sciences, 18: 737-750

Williams AM, Reilly T (2000a). Searching for the stars. Journal of Sport Sciences, I8, 655-656

Williams AM, Reilly T (2000b). Talent identification and development in soccer. Journal of Sports Sciences, 18: 657-667

Yague PH, De la Fuente JM (1998). Changes in height and motor performance relative to peak height velocity: A mixed-longitudinal study of Spanish boys and girls. American Journal of Human Biology, I0(5): 647-660 
Página deixada propositadamente em branco. 